www.volsu.ru

DOI: https://doi.org/10.15688/nsr.jvolsu.2021.2.4

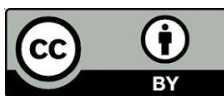

UDC 504.61(470.45)

LBC 28.088л6(2Р-4Вог)

\title{
ENVIRONMENTAL IMPACT ASSESSMENT OF THE SPATIAL ORGANIZATION OF THE NIZHNEKHOPERSKY NATURAL PARK OF THE VOLGOGRAD REGION
}

\author{
Anna V. Kholodenko \\ Volgograd State University, Volgograd, Russian Federation \\ Polina S. Gorbova \\ Volgograd State University, Volgograd, Russian Federation
}

\begin{abstract}
The article considers the problem of territorial protection of nature as a factor impeding the socioeconomic development of settlements located within the borders of the Nizhnekhopersky natural park. The key problem of the functioning of regional specially protected natural territories is the contradiction between the need to protect undisturbed natural-territorial complexes and the development of settlement territories that find themselves in the zone of limited economic activity. The development of settlement territories involves the removal of existing restrictions on the civil circulation of land plots, the construction and reconstruction of capital construction facilities. Solving the problem of economic stagnation by adjusting borders and excluding settlements from the natural park entails the need to conduct an environmental impact assessment of future economic activities in areas seized from specially protected natural areas. The forecast assessment of the consequences of possible anthropogenic impacts on the landscapes and ecosystems of the Nizhnekhopersky natural park after changing its area, functional organization and environmental management regimes in the allocated areas was carried out using a modified network method. The results of the research showed that the strengthening of the anthropogenic press as a result of the implementation of measures for the deployment of processing production, the construction of roads and engineering communications (electrification, gasification), housing construction, as well as due to the increase in recreational load, including the spread of uncontrolled recreation, the environmental efficiency of the natural park will naturally decrease.

Key words: specially protected natural areas, spatial organization, functional zoning, anthropogenic impacts, the Nizhnekhopersky natural park of the Volgograd region.

Citation. Kholodenko A.V., Gorbova P.S. Environmental Impact Assessment of the Spatial Organization of the Nizhnekhopersky Natural Park of the Volgograd Region. Prirodnye sistemy i resursy [Natural Systems and Resources], 2021, vol. 11, no. 2, pp. 27-34. DOI: https://doi.org/10.15688/nsr.jvolsu.2021.2.4
\end{abstract}

УДК 504.61(470.45)

ББК 28.088л6(2Р-4Вог)

\section{ОЦЕНКА ЭКОЛОГИЧЕСКИХ ПОСЛЕДСТВИЙ ИЗМЕНЕНИЯ ПРОСТРАНСТВЕННОЙ ОРГАНИЗАЦИИ ПРИРОДНОГО ПАРКА «НИЖНЕХОПЕРСКИЙ» ВОЛГОГРАДСКОЙ ОБЛАСТИ}

\author{
Анна Викторовна Холоденко \\ Волгоградский государственный университет, г. Волгоград, Российская Федерация \\ Полина Сергеевна Горбова \\ Волгоградский государственный университет, г. Волгоград, Российская Федерация
}

Аннотация. В статье рассматривается проблема территориальной охраны природы как фактора, препятствующего социально-экономическому развитию населенных пунктов, находящихся в границах природного парка «Нижнехоперский». Ключевая проблема функционирования региональных особо охраняемых 


\section{Экология и БИология}

природных территорий - противоречие между необходимостью охраны ненарушенных природно-территориальных комплексов и развитием селитебных территорий, оказавшихся в зоне ограниченной хозяйственной деятельности. Развитие селитебных территорий предполагает снятие существующих ограничений на гражданский оборот земельных участков, строительство и реконструкцию объектов капитального строительства. Решение проблемы экономической стагнации посредством корректировки границ и исключения населенных пунктов из природного парка влечет необходимость проведения оценки воздействия на окружающую среду будущей хозяйственной деятельности на изымаемых из особо охраняемых природных территорий участках. Прогнозная оценка последствий возможных антропогенных воздействий на ландшафты и экосистемы природного парка «Нижнехоперский» после изменения его площади, функциональной организации и режимов природопользования на выделенных участках производилась при помощи модифицированного метода сетевых графиков. Результаты исследования показали, что усиление антропогенного пресса в результате реализации мероприятий по развертыванию перерабатывающего производства, прокладке автомобильных дорог и инженерных коммуникаций (электрификация, газификация), жилищного строительства, а также вследствие роста рекреационной нагрузки, в том числе распространения неконтролируемого отдыха, природоохранная эффективность природного парка будет закономерно снижаться.

Ключевые слова: особо охраняемые природные территории, пространственная организация, функциональное зонирование, антропогенные воздействия, природный парк «Нижнехоперский» Волгоградской области.

Цитирование. Холоденко А. В., Горбова П. С. Оценка экологических последствий изменения пространственной организации природного парка «Нижнехоперский» Волгоградской области // Природные системы и ресурсы. - 2021. - Т. 11, № 2. - С. 27-34. - DOI: https://doi.org/10.15688/nsr.jvolsu.2021.2.4

\section{Введение}

Природный парк, как элемент региональной системы особо охраняемых природных территорий, является нестрогой формой охраны природы, что предполагает реализацию рекреационной и экстенсивной хозяйственной деятельности в соответствии с природным потенциалом территории наравне с осуществлением мероприятий по охране природных комплексов и биологическогого разнообразия [11].

Необходимость сочетания охраны ландшафтов и реализации стратегических мероприятий развития населенных пунктов в границах ООПТ обусловливает возникновение новых систем управления, призванных интегрировать антропогенный элемент в природную среду без снижения экологической устойчивости и сокращения видового разнообразия [3]. При этом первостепенное значение имеет оценка экологических последствий после расширении спектра антропогенных влияний в границах охраняемых природных территорий.

Объектом исследования является природный парк «Нижнехоперский». Цель исследования - анализ изменений экосистем природного парка при увеличении антропогенной нагрузки после изменения его внутренней пространственной организации.
Исследование проводилось при помощи модифицированного метода сетевых графиков (потоковых диаграмм) [5; 13].

\section{Материалы и методы}

Природный парк «Нижнехоперский» образован в соответствии с постановлением Главы Администрации Волгоградской области от 25 марта 2003 г. № 205 и расположен на территории Алексеевского, Кумылженского и Нехаевского муниципальных районов Волгоградской области. Общая площадь 231272,6 га. На территории обозначены четыре функциональные зоны: природоохранная (66745 га, 28,9 \% от территории парка); рекреационная (50857 га, 22 \% от территории парка); агрохозяйственная (37430 га, 16,2\% от площади парка); буферная (78172 га, 33,8 \% от площади парка) [7].

В природном парке охраняются особо ценные природные комплексы: обнажения меловых пород; высокое правобережье Бузулука и участки надпойменной песчаной террасы; черноольшаники у подножия левобережной надпойменной террасы Хопра; склоны балок и нагорно-байрачные леса на правом берегу Хопра; КОТР Шакинская дубрава и участки песчаной степи, луговых сообществ по понижениям и долинам речек; петрофиль- 
ные комплексы на обнажениях мела, мергеля и опоковидных песчаников; березовые колки и бугристые пески с сырыми котловинами; бугристые развеваемые пески ледникового происхождения $[4 ; 9 ; 10]$.

Все ландшафты характеризуются высокой концентрацией редких и исчезающих видов растений и животных, занесенных в Красную Книгу Российской Федерации, Красную Книгу Волгоградской области и списки МСОП [4]. Коэффициент флористического разнообразия 2,5-2,9 [2]. Антропогенная измененность ландшафтов составляет 2,54 балла, что соответствует фоновым показателям Волгоградской области [6].

Природный парк «Нижнехоперский» в качестве одного из ключевых ядер экологического каркаса Волгоградской области участвует в поддержании качества окружающей среды в регионе.

Однако в пределах Кумылженского муниципального района в границах парка полностью или частично располагаются 6 сельских поселений, в пределах Алексеевского муниципального района - 10 сельских поселений и в пределах Нехаевского муниципального района - 5 сельских поселений. В сумме в границах природного парка располагается 54 населенных пункта [6].

Согласно ст. 27 Земельного кодекса РФ [1] и п.п. 4.3 и 4.5 Положения о природном парке «Нижнехоперский» [7], земельные участки, находящиеся в государственной либо муниципальной собственности, расположенные в пределах региональной ООПТ ограничиваются в обороте. В соответствии со статьей
18 Ф3-33 «Об особо охраняемых природных территориях» [12] запрещается изменение целевого назначения земельных участков, находящихся в границах природного парка, за исключением случаев, предусмотренных федеральными законами.

Таким образом, граждане, проживающие на территории ООПТ, в частности льготные категории граждан, и юридические лица не могут получить земельные участки в собственность. Это ограничивает развитие производства, сдерживает привлечение в районы инвесторов, способствует миграционному оттоку населения в города и не позволяет населенным пунктам преодолеть экономическую стагнацию. Ограничение прав граждан и юридических лиц ведет нарастанию конфликта между задачами ООПТ и интересами местного населения (рис. 1).

Вывод земель хуторов из состава природного парка в рамках постановления Администрации Волгоградской области от 08.07.2019 № 321-п [8] позволит привлекать инвестиции в производства по переработке сельскохозяйственной продукции, развивать инфраструктуру, свободно продавать и приобретать земельные участки, что положительно скажется на экономических показателях и качестве жизни населения. Но вместе с тем после снятия ограничений на хозяйственную деятельность на выведенных участках существенно возрастет антропогенная нагрузка. Так как населенные пункты находятся внутри функциональных зон парка, нельзя исключить появления цепных реакций, обусловленных горизонтальными и вертикальными веще-

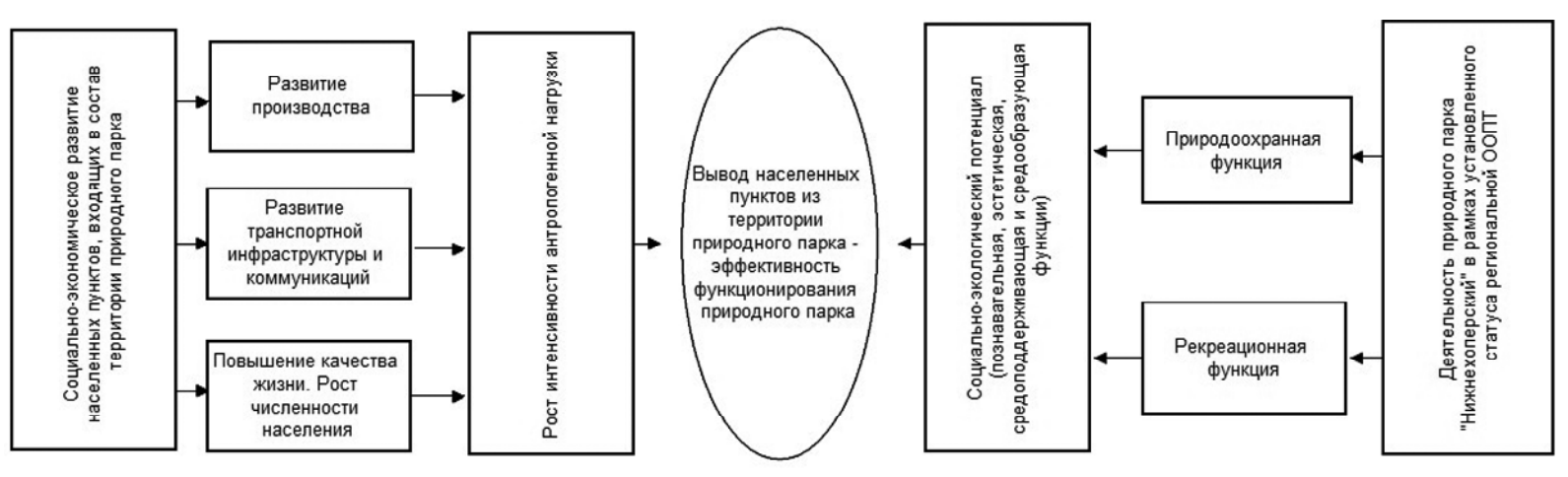

Рис. 1. Конфликтность задач региональной ООПТ и социально-экономического развития территориальных образований 


\section{ЭКОЛОГИя И БИОЛОГИЯ}

ственно-энергетическими связями между природными и антропогенными ландшафтами.

Прогноз потенциальных изменений природоохранной эффективности природного парка выполнен аналитическим модифицированным методом потоковых диаграмм - сетевых графиков. Метод основан на учете направлений воздействий с анализом ответных реакций отдельных природных компонентов и системы в целом. Сетевые графики позволяют выявить связи между элементами экосистем и проследить динамику их изменения [5; 13].

\section{Результаты и обсуждение}

Участки, предлагаемые к выводу из состава природного парка «Нижнехоперский» включают селитебные территории общей площадью 7792,4 га [6], что составляет 3,4 \% от площади ООПТ. Таким образом, после изъятия 54 населенных пунктов площадь парка по предварительным расчетам сократится с 231272,6 га до 223480,2 га.

В разрезе функциональных зон изменение площади выглядит следующим образом: природоохранная зона уменьшится на 1851,2 га, что составляет $2,8 \%$ от площади зоны; рекреационная зона сократится на 5329,2 га, что составляет $10,5 \%$ от площади зоны; буферная зона потеряет 612 га, что равно $0,8 \%$ от площади зоны (см. таблицу).

Исключение из границ природного парка исключительно нарушенных земель населенных пунктов не повлечет утрату ландшафтной репрезентативности, но существенно повысит уязвимость мозаичных степных сообществ в результате нарушения целостности функциональных зон и роста внутреннего антропогенного давления.

К числу потенциальных угроз, источниками которых являются населенные пункты, относятся: развитие перерабатывающих производств (животноводческих комплексов, предприятий по переработке растениеводческой продукции); прокладка автомобильных дорог и коммуникаций; жилищное строительство и нерегулируемая рекреация, следствием которой являются замусоривание водных объектов и береговой полосы твердыми коммунальными отходами, пожары и дигрессия растительных сообществ (см. рис. 2).

Улучшение качества жизни после вывода территорий будет способствовать росту численности населения, что в итоге потребует расширения площадей населенных пунктов для дальнейшей застройки. Вместе с тем возможно ухудшение экологических параметров среды и снижение ее комфортности, как для человека, так и для представителей других видов. Вследствие можно ожидать снижения рекреационной привлекательности и эстетической ценности ландшафтов, распространения синантропной флоры и фауны.

Возрастающая антропогенная нагрузка в первую очередь скажется на землях, прилегающих к населенным пунктам, а затем - на смежных с ними посредством транслокальных взаимодействий.

Основными последствиями могут быть: изменение фоновых параметров качества окружающей среды, сокращение популяций охраняемых видов, упрощение зональных и интразональных сообществ.

Согласно закону внутреннего динамического равновесия, изменение одних элементов в системе приводит к структурно-функциональным трансформациям других. Незначительные на первый взгляд изменения параметров среды могут повлечь масштабные отклонения энергетического и вещественного баланса в крупных иерархических единицах.

Характеристика участков исключаемых из состава природного парка «Нижнехоперский» относительно функциональных зон

\begin{tabular}{|l|c|c|c|}
\hline $\begin{array}{c}\text { Функциональная } \\
\text { зона }\end{array}$ & $\begin{array}{c}\text { Количество } \\
\text { участков }\end{array}$ & $\begin{array}{c}\text { Средний \% } \\
\text { антропогенной } \\
\text { нарушенности участков }\end{array}$ & $\begin{array}{c}\text { Количество участков, в близи } \\
\text { которых встречаются редкие и } \\
\text { исчезающие виды }\end{array}$ \\
\hline Приро доо хранная & 10 & 53 & 5 \\
\hline Рекреационная & 36 & 60 & 11 \\
\hline Буферная & 8 & 63 & 5 \\
\hline
\end{tabular}

Примечание. Составлено по: [3; 13]. 
А.В. Холоденко, П.С. Горбова. Оценка экологических последствий изменения пространственной организации

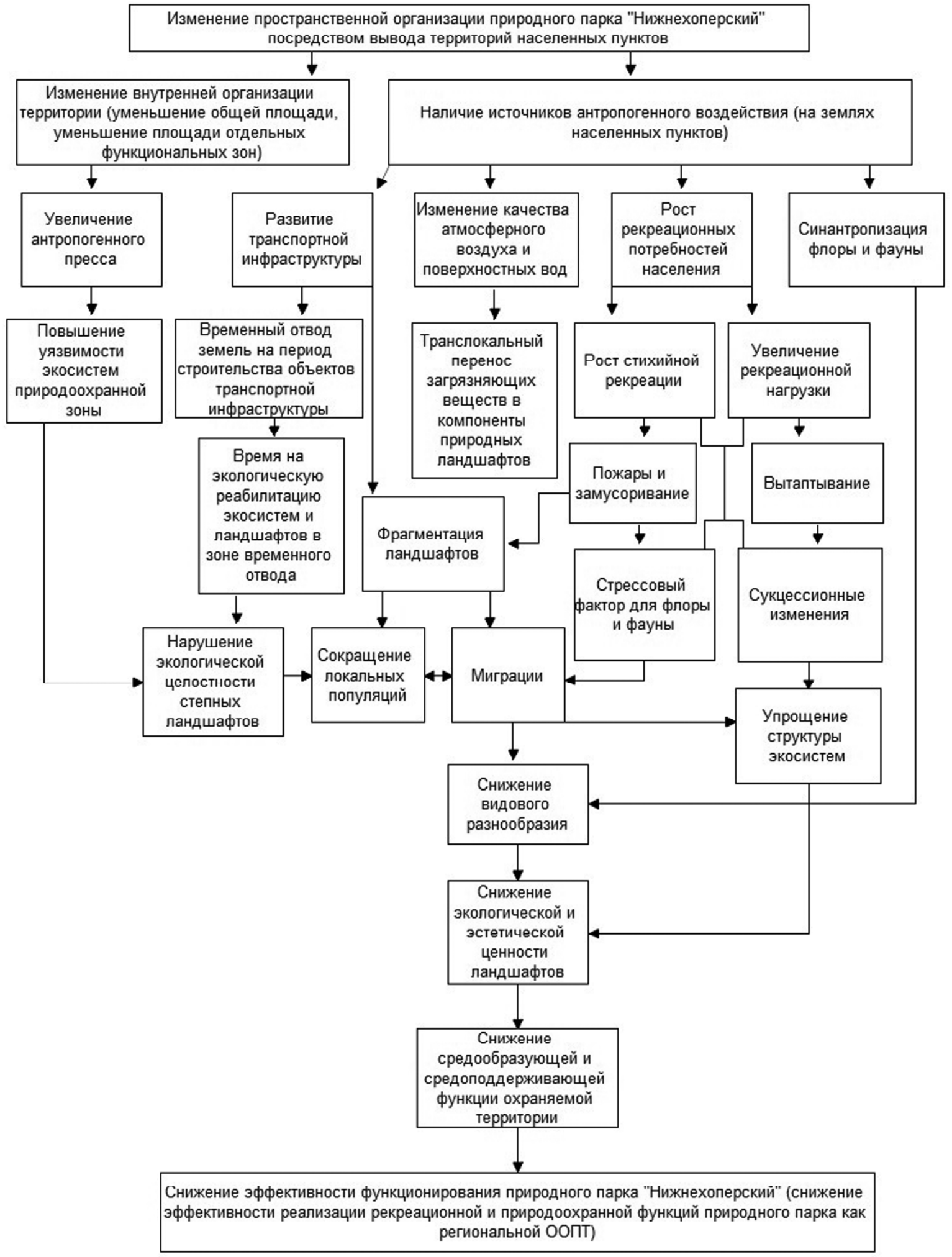

Рис. 2. Диаграмма потоков оценки воздействия изменения пространственной организации природного парка «Нижнехоперский» Волгоградской области на эффективность его функционирования в статусе региональной ООПТ 
Смещение существующего равновесия между природными и природно-антропогенными системами в природном парке «Нижнехоперский» в будущем может привести к нарушениям средоформирующей и средоподдерживающей функций естественных ландшафтов.

\section{Заключение}

Прогнозный анализ методом сетевых графиков подтвердил закономерное снижение природоохранной эффективности функционирования природного парка «Нижнехоперский» при выводе населенных пунктов.

Учитывая значимость социально-экономического развития территорий для устойчивого развития и, следовательно, необходимость проведения корректировки границ природного парка, следует:

1. Организовать регулярную систему мониторинга редких и исчезающих видов, встречающихся на границах населенных пунктов.

2. Создать вокруг выводимых участков переходные зоны по типу экотонов для минимизации негативного воздействия нынешней и будущей хозяйственной деятельности на естественные ландшафты.

3. Следить за строгим соблюдением природоохранного законодательства в границах охраняемых зон. Увеличить количество рейдов, направленных на выявление нарушителей.

4. Организовать эколого-просветительскую работу с местным населением и посетителями относительно решений по корректировке границ парка и изменениями в функциональном зонировании.

5. Разработать инвестиционные программы, направленные на эко-ориентированное развитие сельской местности.

\section{СПИСОК ЛИТЕРАТУРЫ}

1. Земельный кодекс Российской Федерации от 25.10.2001 № 136-Ф3 (ред. от 31.12.2017) // Собрание законодательства РФ. - 2001 . - 29 окт. (№ 44). Ст. 4147.

2. К флоре волгоградского Прихоперья и Нижнехоперского природного парка / В. А. Сагалаев [и др.] // Известия Волгоградского государственного педагогического университета. Сер. «Есте- ственные и физико-математические науки». 2004. - № 4 (09). - С. 77-85.

3. Кириллов, С. Н. Управление антропогенными воздействиями в природных парках Волгоградской области / С. Н. Кириллов, А. В. Холоденко // Вестник ВолГУ. - 2011. - № 2. - С. 40-48.

4. Комплексное экологическое обоснование территории природного парка «Нижнехоперский», для придания статуса особо охраняемой природной территории регионального значения. - Станица Букановская : [б. и.], 2009. - 135 с.

5. Корнилова, И. Е. Методы ОВОС, их применение для выявления значимых воздействий от мелиоративных систем / И. Е. Корнилова, Д. К. Жумамбетова, Д. Уралова // Вестник науки Костанайского социально-технического университета имени академика Зулхарнай Алдамжар. - 2016. - № 2. C. $22-26$.

6. Материалы по внесению изменений в комплексное экологическое обследование территории природного парка «Нижнехоперский», обосновывающие придание статуса ООПТ регионального значения. - Станица Букановская : [б. и.], 2015. $-189 \mathrm{c}$.

7. Об утверждении Положения о природном парке «Нижнехоперский»: Постановление Администрации Волгоградской области от 22 августа 2016 года № 455-п // Консорциум Кодекс: электронный фонд правовой и нормативно-технической документации. - Электрон. текстовые дан. - Режим доступа: https://docs.cntd.ru/document/441628117 (дата обращения: 07.10.2020). - Загл. с экрана.

8. Об утверждении Порядка создания, изменения категории, профиля, площади, границ, установленного режима особой охраны (включая особенности функционального зонирования) и упразднения особо охраняемых природных территорий регионального значения: постановление Администрации Волгоградской области от 08.07.2019 № 321-п // Консорциум Кодекс: электронный фонд правовой и нормативно-технической документации. Электрон. текстовые дан. - Режим доступа: https:// docs.cntd.ru/document/561422708 (дата обращения: 10.12.2020). - Загл. с экрана.

9. Паршутина, Л. П. Нижнехоперский природный парк - крупнейший резерват степей в Волгоградской области / Л. П. Паршутина, Т. Г. Пономарева, Л. А. Ящерицына // Степной бюллетень. 2008. - № 25. - C. 20-25.

10. Пономарева, Т. Г. Природный парк «Нижнехоперский» / Т. Г. Пономарева, Л. А. Ящерицина // Здоровье и экология. -2005 . - № 6. - С. 27-28.

11. Стишов, М. С. Охраняемые природные территории Российской Федерации и их категории / М. С. Стишов, Н. Дадли. - М. : Всемирный фонд дикой природы (WWF), 2018. - 248 c. 
12. Федеральный закон от 14 марта 1995 г. № 33Ф3 «Об особо охраняемых природных территориях» (с изменениями и дополнениями) // Собрание законодательства Российской Федерации. - 1995. № 12. - Ст. 1024 .

13. Ore, O. Graphs and Their Uses / O. Ore. N. Y. : Random House, 1967. - 175 p.

\section{REFERENCES}

1. Zemel'nyj kodeks Rossijskoj Federacii ot 25.10.2001 № 136-FZ (red. ot 31.12.2017) [The Land Code of the Russian Federation of October 25, 2001 No. 136-FZ (as amended on December 31, 2017)]. Sobranie zakonodatel'stva RF [Collected Legislation of the Russian Federation], 2001, Oct. 29, no. 44.

2. Sagalaev V.A. K flore volgogradskogo Prihoper'ja i Nizhnehoperskogo prirodnogo parka [To the flora of the Volgograd Prikhopyorie and Nizhnekhopersky Natural Park]. Izvestija Volgogradskogo gosudarstvennogo pedagogicheskogo universiteta. Ser. "Estestvennye i fizikomatematicheskie nauki» [Science Journal of Volgograd State Pedagogical University Natural and Physical and Mathematical Sciences], 2004, no. 4(09), pp. 77-85.

3. Kirillov S.N., Holodenko A.V. Upravlenie antropogennymi vozdejstvijami v prirodnyh parkah Volgogradskoj oblasti [Management of Anthropogenic Impacts in Natural Parks of the Volgograd Region]. Vestnik Volgogradskogo gosudarstvennogo universiteta [Science Journal of Volgograd State University], 2011, no. 2, pp. 40-48.

4. Kompleksnoe jekologicheskoe obosnovanie territorii prirodnogo parka «Nizhnehoperskij», dlja pridanija statusa osobo ohranjaemoj prirodnoj territorii regional'nogo znachenija [Complex Ecological Substantiation of the Territory of the Nizhnehopersky Natural Park, for Giving the Status of the Specially Protected Natural Territory of Regional Value]. Stanitsa Bukanovskaya, 2009. 135 p.

5. Kornilova I.E., Zhumambetova D.K., Uralova D. Metody OVOS, ih primenenie dlja vyjavlenija znachimyh vozdejstvij ot meliorativnyh system [Environmental Impact Assessment Methods, Their Application for Detection of Significant Effects from Reclamation Systems]. Vestnik nauki Kostanajskogo social'notehnicheskogo universiteta imeni akademika Zulharnaj Aldamzhar [Science Journal of Kostanay Social and Technical University Named After Academician Zulharnai Aldamzhar], 2016, no. 2, pp. 22-26.

6. Materialy po vneseniju izmenenij $v$ kompleksnoe jekologicheskoe obsledovanie territorii prirodnogo parka "Nizhnehoperskij», obosnovyvajushhie pridanie statusa OOPT regional'nogo znachenija [Materials for Amending a
Comprehensive Environmental Survey of the Territory of the Nizhnekhopersky Natural Park, Substantiating the Granting of the Status of a Protected Area of Regional Significance]. Stanitsa Bukanovskaya, 2015. 189 p.

7. Obutverzhdenii Polozhenija o prirodnom parke «Nizhnehoperskij» : Postanovlenie Administracii Volgogradskoj oblasti ot 22 avgusta 2016 goda № 455-p [On Approval of the Regulations on the Nizhnekhopersky Natural Park: Resolution of the Administration of the Volgograd Region Dated August 22, 2016 No. 455-p]. Konsorcium Kodeks: jelektronnyj fond pravovoj $i$ normativno-tehnicheskoj dokumentacii [Consortium Codex: Electronic Fund of Legal and Regulatory Technical Documentation]. URL: http://docs.cntd.ru/ document/441628117 (accessed 07.10.2020).

8. Obutverzhdenii Porjadka sozdanija, izmenenija kategorii, profilja, ploshhadi, granic, ustanovlennogo rezhima osoboj ohrany (vkljuchaja osobennosti funkcional'nogo zonirovanija) i uprazdnenija osobo ohranjaemyh prirodnyh territorij regional'nogo znachenija : postanovlenie Administracii Volgogradskoj oblasti ot 08.07.2019 № 321-p [On the Approval of the Procedure for the Creation, Change of the Category, Profile, Area, Boundaries, the Established Regime of Special Protection (Including Features of Functional Zoning) and the Abolition of Specially Protected Natural Areas of Regional Significance: Decree of the Administration of the Volgograd Region of 08.07.2019 No. 321-p]. Konsorcium Kodeks: jelektronnyj fond pravovoj $i$ normativno-tehnicheskoj dokumentacii [Consortium Codex: Electronic Fund of Legal and Regulatory Technical Documentation]. URL: http://docs.cntd.ru/document/ 561422708 (accessed 10.12.2020).

9. Parshutina L.P., Ponomareva T.G., Jashhericyna L.A. Nizhnehoperskij prirodnyj park krupnejshij rezervat stepej v Volgogradskoj oblasti [Nizhnekhopersky Natural Park - The Largest Steppe Reserve in the Volgograd Region]. Stepnoj bjulleten' [Steppe Bulletin], 2008, no. 25, pp. 20-25.

10. Ponomareva T.G., Jashhericyna L.A. Prirodnyj park «Nizhnehoperskij» [Nizhnekhopersky Natural Park]. Zdorov'e i jekologija [Health and Ecology], 2005, no. 6, pp. 26-28.

11. Stishov M.S., Dadli N. Ohranjaemye prirodnye territorii Rossijskoj Federacii $i$ ih kategorii [Protected Natural Areas of the Russian Federation and Their Categories]. Moscow, WWF, 2018. 248 p.

12. Federal'nyj zakon ot 14 marta 1995 g. № 33FZ «Ob osobo ohranjaemyh prirodnyh territorijah» (s izmenenijami i dopolnenijami) [The Federal Law of March 14, 1995 No. 33-FZ «On Specially Protected Natural Areas» (with amendments and additions)]. Sobranie zakonodatel'stva $R F$ [Collected Legislation of the Russian Federation], 1995, no. 12.

13. Ore, O. Graphs and Their Uses. New York, Random House, 1967. 175 p. 


\section{ЭкоЛОГия и БИоЛОГИя}

\section{Information About the Authors}

Anna V. Kholodenko, Candidate of Sciences (Geography), Associate Professor, Department of Ecology and Nature Resources Management, Volgograd State University, Prosp. Universitetsky, 100, 400062 Volgograd, Russian Federation, kholodenko@volsu.ru

Polina S. Gorbova, Student, Department of Ecology and Nature Resources Management, Volgograd State University, Prosp. Universitetsky, 100, 400062 Volgograd, Russian Federation, gorbova.polina@mail.ru

\section{Информация об авторах}

Анна Викторовна Холоденко, кандидат географических наук, доцент кафедры экологии и природопользования, Волгоградский государственный университет, просп. Университетский,100, 400062 г. Волгоград, Российская Федерация, kholodenko@volsu.ru

Полина Сергеевна Горбова, студент кафедры экологии и природопользования, Волгоградский государственный университет, просп. Университетский,100, 400062 г. Волгоград, Российская Федерация, gorbova.polina@mail.ru 